\title{
Realizing Research Impact and the Experience of a Malaysian University
}

\author{
Shaliza Ibrahim ${ }^{1,2, *}$ \\ ${ }^{1}$ Institute of Research Management and Services, University of Malaya,50603 Kuala Lumpur, Malaysia \\ ${ }^{2}$ Institute of Ocean and Earth Sciences, University of Malaya, 50603 Kuala Lumpur, Malaysia
}

"Corresponding author email:

shaliza@um.edu.my

Received date: 9 Dec 2018

Published date: 31 Dec 2018

How to cite:

Ibrahim, S. (2018). Realizing

Research Impact and the

Experience of a Malaysian

University. Journal of Research

Management \& Governance, 1(1),

38-43. Retrieved from https://

ejournal.um.edu.my/index.php/

JRMG/article/view/14978

DOI:

https://doi.org/10.22452/

jrmg.vol1no1.3

\begin{abstract}
This paper touches on a range of aspects that affect the realization of research impact. Malaysia has invested significantly in research and we have world class researchers who have proven themselves with high impact publications. However, there is still a lack of clear connection when it comes to relating research output to resources. This paper recommends proper initial research planning involving multi-sectorial stakeholders, and identification of impact and impact pathways in conceptualizing research projects. Strong institutional support in the form of professional research managers to assist researchers in research processes is important to ensure that the research activities are run smoothly and monitored well. Initiatives to enhance researchers networking, mobility and competency through relevant training programmes will encourage our academics to expand their horizon and generate new ideas for research. Considering the amount of investment that has been made and the conducive environment that we have at universities, it may seem that we are not fully capturing or extracting all the results and products of our research endeavour. It is thus highly desired that Malaysia should have sound database and data management system to capture all the work that has been done and make the information accessible to research managers as well as researchers to do strategic analyses.
\end{abstract}

Keywords: research impact; research development; assessment tool

\section{INTRODUCTION}

Research and development in Malaysia can be traced back to the mid and early 1900s, with the founding of research institutes. Research institutes were established for specific niche areas -- the Rubber Research Institute (RRI), the Institute of Medical Research (IMR), Forest Research Institute Malaysia (FRIM), Malaysian Palm Oil Board (MPOB), and the Malaysian Agricultural Research and Development Institute (MARDI), to name a few. Naturally, the outcome from these research institutes has to do with the advancement of the respective commodities or economic sectors that each of them addresses.

Universities were first established primarily to provide tertiary education i.e. teaching and learning, and to produce the workforce for a growing nation. Universities have also contributed significantly in research, with the increase in expertise in various academic disciplines. Universities enjoy the advantage of having a continuous flux of students and graduates, which perpetuate the academic momentum and energy, as well as expanding the network of stakeholders. Research continues to thrive under this 
vibrant environment with our academics engaging in cutting-edge and high impact research projects. This in turn, keeps the knowledge and skills taught to our students relevant and alive. Research inevitably, is an integral part of academia.

As one of the fastest growing economies in Southeast Asia, Malaysia has nearly achieved its aspiration to be the education hub for the region, and in the last decade it has progressed steadily towards becoming a world class player in research with multi-fold increase in the output, even surpassing China and Korea in the rate of growth of indexed publications.

The bulk of research funds for public institutions come from the government, but through the expansion of research network and collaborations, more funds are now coming from the private sector and international agencies. In line with this development, our researchers are becoming more receptive to the need to deliver beyond the academic output that is to also be thinking of the socio-economic impact, from the time of conceiving their research ideas.

\section{IMPACT OF UNIVERSITIES' RESEARCH}

Evaluating the impact of university research in Malaysia puts into consideration a broad range of parameters, from the immediate academic output in the form of journal papers and talents, to more direct outcome with stakeholders with the uptake of products or services by industries and communities.

It is fair to say that universities are the keepers of fundamental research, which is essential in discovering new knowledge. University researchers, supported by an ecosystem comprising teams of experts, library resources, physical infrastructure and special facilities, have a conducive setting to conduct experiment-based, curiosity-driven fundamental research which generates new ideas that can be published.

Publishing research results in academic journals marks the climax of an academic research and is the professional way to disseminate findings. Academic journals are ranked in terms of their impact, prestige and influence. Papers in indexed journals are accessible by the research community all over the world, and a measure of the impact is the number of citations received in the published literature. The $h$ -index gives an indication of the productivity and citation impact of a researcher.

As paper citations increase through cross-referencing of papers, the researchers and institutions with which they are affiliated become better-known. This potentially opens opportunities for networking and collaborations among researchers, which augurs well for the respective institutions' as well as the country's reputations. The number of citations per researcher is used as a criterion in world university rankings.

Apart from publishing papers, a good number of academic researchers are inclined towards solving real life issues. This results in a range of outcomes from policy papers that could influence government policies to innovations that can be commercialized and translated to society.

In justifying the investment of public funds for research and development, universities have been under greater pressure to have a more pragmatic approach in research, with emphasis on social good. At the same time, prestigious private and international grants including Toyota Foundation, Sumitomo, and Global Challenge Research Fund (UK) are all looking at impact to society. In Malaysia, the quadruple helix model has been put forward to ensure input from the government, industries, academia and society in creating an open innovation system with multi-sectorial collaborations. The availability of suitable funding has attracted our researchers to embark in community-centred projects and become better at adapting to carrying out research with direct benefits to the people. 
Applied research produce inventions, technologies, designs, or works of art which are protected as intellectual properties in the form of patents, trademarks and copyrights. Marketable research outputs generate interests from potential investors who may provide funds to co-develop products or technologies for a full-scale application if the economic advantage is clear. A challenge faced by academics to take their research products to the next level for commercialization is in getting the right match for a business partner. Academics are generally not equipped to market their products, plus their time is better spent concentrating on their research and teaching duties.

Opportunities are made available through pre-commercialization grants, accelerator programmes on developing business model canvasses and pitching to investors, start-up funds, and entrepreneurial programmes, such as those provided by the Malaysian Global Innovation and Creativity Centre (MaGIC), CRADLE Sdn Bhd, and PlatCOM Ventrues Sdn Bhd. However, institutional support is still essential for researchers to progress to the next level with their innovations. Technology transfer offices (TTOs) act as conduits to promote research products. Skill and experienced professional innovation managers at TTOs can effectively bridge the gap between academia and the commercial world, which otherwise remains a major hurdle for uptake by the corporate sector.

The Ministry of Education had twice commissioned impact studies on Research Universities - for the first five years and for the second five years period to mark one decade of RUs. The study looked at Talent Development, Research Prominence, Wealth Creation and Bridging the Grand Challenge. Details on these studies can be obtained from the final report.

\section{ASSESSMENT TOOL}

The Malaysian Research Assessment (MyRA) instrument was developed in-house by the then Ministry of Higher Education, with the establishment of Research Universities in 2006. MyRA criteria are: Quantity and Quality of Researchers, Quantity and Quality of Research, Postgraduates, Innovation, Professional Services and Gifts, Networking and Linkages, and Support Facilities including accreditation of our laboratories.

The parameters which are being assessed include number of journal and conference papers, citations, h-index, patents, copyright, trademarks, and income generated from commercialization of research products, as well as licensing and spin-offs. Number of graduates (talents), amount of funding, number of projects and principal investigators are also counted, as they reflect the strength and capacity of the university in conducting research and obtaining research funds. Awards and recognition received by academics are included as achievement as it shows the leadership strength of the institution.

Since it started about ten years ago, there are now two versions of MyRA. The main difference between the two versions is the benchmarks. Research Universities are subjected to the second version of MyRA which is more output-focused, whereas the newer / younger universities use the first version which still has emphasis on input.

MyRA puts high weightage on publications and citations, thus stressing the importance of academic prominence. With the advent of more community-based projects, we are searching for the best method to measure qualitative outcomes. A rubric method with star rating is currently used to evaluate the impact of community-based projects in terms of the extent of effect on the community, how transformational and sustainable.

MyRA audits are conducted every year, and the evaluations are done as a post-award monitoring exercise to assess the achievement of the research project and the return on investment. We are now beginning to emphasize the importance of identifying potential impact of a study from the time the 
research proposal is developed or when ideas are conceived. Researchers are required to explain the potential outcome and impact of their work in the proposals. We may see a move towards qualitative assessment of impact that we are seeing in the UK and other countries. It may start by modelling after the UK Research Evaluation Framework (REF), but with adjustments to suit what is best for Malaysia, and eventually there might be a version specially catered for Malaysian research assessment.

Another instrument used for Malaysian institutions is the SETARA rating which is more on teaching and learning (education), but takes into account the quality of research since this has direct influence on education.

While still measuring input to research in terms of student numbers, grant quantum and researchers' qualification, and looking at traditional research output, we are mindful about the importance of societal or external impact as practiced in the UK. The MyRA instrument undergoes regular reviews to incorporate changes as we evolve. In assessing Malaysian institutions we should acknowledge the various categories of universities with different levels of maturity.

\section{UNIVERSITY OF MALAYA'S JOURNEY AND EXPERIENCE}

Among the earliest publications by UM academics from 1960s include a paper entitled Contemporary Urbanisation in Malaysia published in Asian Survey by the late Professor Hamzah Sendut, and a letter on Subdivisions of Estates in Malaya (1951-1960) published in Malayan Economic Review by none other than Royal Professor Ungku Abdul Aziz. These articles, published in Web of Science-indexed journals and addressing pertinent socio-economic issues of the time, would have met the deliverables criteria for research today. UM's first patent was granted in 1980 for the PVC hand pump invented by the research team of Professor Goh Sing Yau through an international fund. The pump had benefitted communities in 11 countries including Africa.

Research at UM from the early days was driven by the passion and dedication of our academics who truly enjoyed their work and believed in the importance of their contribution. Government funding that started coming in the 1980s provided further support and motivation for our research work to grow from strength to strength. The Intensification of Research in Priority Areas (IRPA) programme was introduced in 1988 to strengthen the system of research and development financing under the provisions of the then Ministry of Science, Technology and Environment (MOSTE). Research funding continued over the next decades with the Ministry of Education introducing its Scheme Research Programmes, as well as other ministries and agencies having their respective R\&D allocations. In 2006 when UM was accorded Research University (RU) status along with three other universities, we received annual block grants to support research intensification expected of RUs.

UM's research evolved from individual projects to programmes incorporating wider disciplines, focusing on common themes or issues to solve, and researchers were able to find their footing or hone their expertise in their respective areas of interest. In 2010, UM leadership imposed the requirement to publish in ISI-cited journals as part of the annual appraisal for all academics, who again rose to the challenge to overcome any psychological barriers and delivered their KPIs. Then the High Impact Research (HIR) progamme was introduced, specifically with the aim of getting high impact publications in top tier journals. Analyses have shown that the HIR did contribute significantly towards increasing the numbers of high impact publications, which are now garnering high citation counts and partly contributing to putting UM among the top ranked universities in the world.

In realizing the need to stress on trans-disciplinary research for a more holistic approach in problem solving, UM created Flagship projects, followed by Grand Challenge research programmes. Yet 
faster and more tangible external impacts were realized through Community Engagement projects managed by UM Community and Sustainability Centre (UMCares), prototype grants by UM Centre for Innovation and Commercialization (UMCIC) and Living Lab project by the then Sustainability Science research cluster. At the national level, there was the Knowledge Transfer Programme (KTP). Through these initiatives, the impacts on society were more evident and encouraging but sustaining the benefits may be an area that needs further support.

UM researchers in recent years have seen tremendous success in securing international research grants -- $400 \%$ increase both in terms of numbers of projects and grant quantum over the last three to four years. Factors that could have contributed to this increase are that researchers are forced to apply for international grants due to limited internal and local funds, researchers are more confident having seen their work published in high impact journals and getting good citation counts, and they are gaining more contact or linkage with potential international collaborators. However, one important strategy was to create a unit with a dedicated research manager solely to look for calls for international grants, the requirements and giving one-on-one assistance in completing and submitting the applications. Impact in international partnerships clearly shows much higher citations for publications compared to papers with no international collaboration.

In 2015, UM became a collaborative partner for BPKI, JPT to implement a project on enhancing Malaysian Research Management and Governance funded by the Newton Ungku Omar Fund. Four key areas are full economic costing for research, data curation and repository, research impact, and professional research managers. We have had the opportunity to learn more about REF in the UK.

UM would like to ensure that the research momentum is sustained so as to further enhance interdisciplinary research as this is important not only to optimize resources but also to provide integrated solutions to problems. It is also desirable for us to balance applied and fundamental research because it is vital for new discoveries to be supported by sound theory and fundamentals.

\section{CONCLUSIONS}

Realizing research impact requires both top-down and bottom-up approaches that are well aligned and complementary to each other. Research directions should not only be in line with the organisation's strategies, vision and mission, the national agenda, and universal trends, but should also take into account current research strengths and emerging areas. While maintaining high impact publications as testament to the quality of work carried out, we need to show significant external or societal impact. For government funders, what is probably more important is to clearly relate an output to the resource in order make better judgement for future planning.

Areas to facilitate in enhancing research impact are as follows:-

- $\quad$ stakeholders involvement in conceiving ideas for research

- identification of impact and impact pathways in proposal writing

- $\quad$ institutional support to administer research management processes

- $\quad$ researchers competency in keeping up with rapid changes

- comprehensive database to track progress and analyse performance

We need to be more adept with engaging stakeholders from all sectors of the economy even before the conception of a research topic and identifying impact and impact pathway during the planning stage. If a system is put in place for stakeholders' engagement and establishing impact pathway, monitoring impact and determining the returns on investment will be more straight-forward. The current practice of tracing back "how it all began" for a particular research outcome, is often 
cumbersome because it could mean going back many years of work and going through different sources of funding at different stages of the research.

Research can benefit much from a conducive ecosystem that ensures good support services and facilities. While our researchers spend time keeping up with new subject areas and technologies, as well as looking for grants, they need the assistance of professional research managers who are dedicated in seeing to the smooth-running of all research processes from proposal writing, budgeting, and submission to procurement and expenditure, progress monitoring, project closure and reporting of impact.

The U21 Ranking of National Higher Education Systems 2018, evaluating research performances of 50 countries has put Malaysia at number 26 for Overall Rank, 33 for Connectivity, 15 for Environment and 12 for Resources but a poor rank of 42 for Output. U21 Output is measured in terms of quality of publications, PhD graduates, employability and throughputs relative to the researchers. Despite our numbers of PhD graduates increasing, there is probably a need to have a bigger plan and strategy for the country's readiness to employ PhD graduates at suitable levels in industries and means to sustain funding for the publication of high impact papers. At the university level, we can heighten connectivity through stakeholders' engagement and global partnership in research. Increasing international collaborations also requires very focused effort and adopting practices compatible with those of our potential partners.

Supporting researchers' mobility and interactions with stakeholders is relevant in enhancing their outlook, perspectives and competency. Hence, initiatives geared towards this effort would certainly be beneficial to our researchers.

Finally, we are in dire need of a comprehensive database that is accessible to researchers and research managers. A data management system for data on research, as well as research data sets, needs to be established as this will provide means for strategic analyses and facilitate the formulation of research ideas and direction.

\section{REFERENCES}

Ibrahim, S. (2014, September 07). Role for RUs as Nation Moves Up, Sunday Star, p. 4-5.

Malaysia Education Blueprint 2013-2025 (2013). Ministry of Education Malaysia: Malaysia.

Malaysian Research Management \& Governance (MRMG) (2018), Vol 1, University of Malaya Press: Malaysia

Malaysian Research Management \& Governance (MRMG) (2018), Vol 2, University of Malaya Press: Malaysia

Research Universities: Continuing as the Engine of Growth for Nation Building 2013-2016 (2018). University of Malaya Press: Malaysia

Research Universities: Impact of Malaysian Research Universities as the Engine of Growth for Nation Building (2014). USIM Publisher: Malaysia

Research Universities 2007-2016: Our Story (2018). University of Malaya Press: Malaysia 